\section{INTRACRANIAL METASTASES}

BY

PETER RICHARDS, M.A., M.B., M.R.C.P.

Research Assistant, Department of Neurosurgery, Atkinson Morley's Hospital, London

AND

WYLIE McKISSOCK, M.S., F.R.C.S.

Neurosurgical Surgeon, St. George's Hospital, London

[With Special Plate]

Surgical treatment is rarely considered when an intracranial metastasis is suspected, even when the primary tumour has previously been excised. We present here a study of the 389 patients with secondary intracranial tumours seen at this hospital in the years 1946-60, inclusive, in an attempt to evaluate the possibilities for useful surgical treatment and to illustrate the unpredictable behaviour of some tumours.

The cases are selected in the sense that patients with intracranial metastases are usually referred here only if the primary tumour is either unsuspected or not evident, or if several years have elapsed since excision of a primary tumour and a coincidental benign intracranial tumour has to be excluded.

\section{Criteria for Diagnosis}

In this series $65 \%$ of the metastases originated from bronchogenic carcinoma (Table I). There were 213 men and 39 women. The criteria used for making the diagnosis in these cases are summarized in Table II. It will be seen that in $17 \%$ no primary tumour was detectable on the chest film taken on admission. The other sites of origin were arrived at by histological study of the metastasis, together with previous or later histological examination of the primary in all but four cases. Professor T. Crawford reported on the histology of the great majority of the metastases.

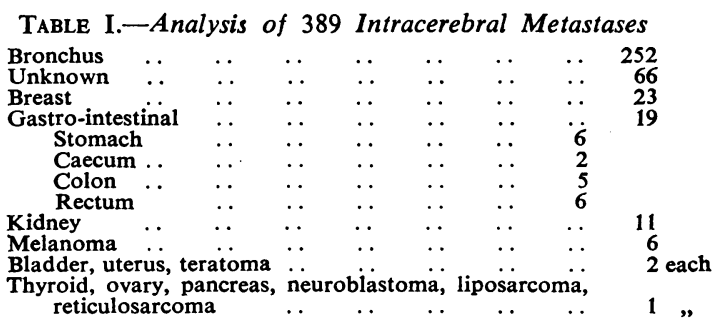

TABle II.-Criteria for Diagnosis of Metastases from Bronchial \begin{tabular}{c|c|c|c|c|c}
\hline $\begin{array}{c}\text { Biopsy of } \\
\text { Metastasis }\end{array}$ & $\begin{array}{c}\text { C.X.R. } \\
\text { Pos. }\end{array}$ & $\begin{array}{c}\text { C.X.R. } \\
\text { Neg. }\end{array}$ & $\begin{array}{c}\text { No } \\
\text { C.X.R. }\end{array}$ & Total & $\begin{array}{c}\text { Necrop- } \\
\text { sies }\end{array}$ \\
\hline
\end{tabular}

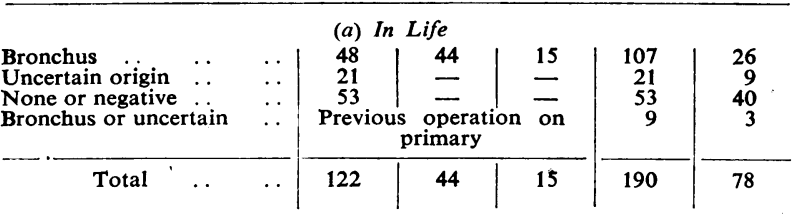

(b) At Necropsy Only

\begin{tabular}{|c|c|c|c|c|}
\hline $\begin{array}{l}\text { Uncertain origin } \\
\text { None or negative }\end{array}$ & $\begin{array}{ll}. & \\
\cdots & \end{array}$ & $\begin{array}{l}15 \\
32\end{array}$ & $\begin{array}{r}3 \\
12\end{array}$ & $\begin{array}{l}18 \\
44\end{array}$ \\
\hline Total & $\ldots$ & 47 & 15 & 62 \\
\hline
\end{tabular}

There were 14 necropsies which are not included in this table. In nine of which metastases were confirmed to have the appearance of bronchogenic carcinoma no definite primary tumour was found. In the remaining five only the brain was examined.
Four tumours described on biopsy as being metastases were said at necropsy to be gliomas, but in two of these cases (examined elsewhere) no histological studies were made. Four metastases were later found to have arisen from sites other than those suggested by the appearance of the biopsy. Four tumours thought from the biopsy histology to be gliomas were at necropsy proved to be carcinomatous metastases.

The 389 cases of intracranial metastasis represent $10 \%$ of all verified intracranial neoplasms seen here during 1946-60. Necropsies were performed on 213.

\section{Survival}

The survival of the largest groups is shown in Table III according to treatment. "Early death" includes all patients dying in this hospital with or without operation. The most striking feature is the high mortality following biopsy of metastases, usually

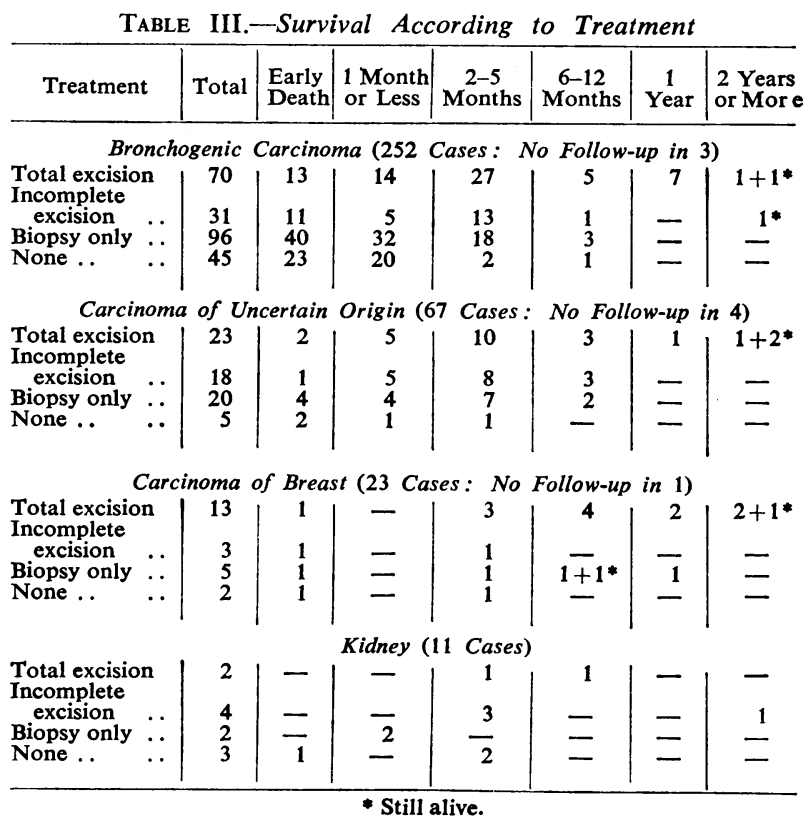

from severe cerebral oedema. The high mortality is partly because patients having biopsy only were often in poorer condition than those having further procedures. Considering the four groups-bronchus, uncertain origin, breast, and kidney -84 of 123 patients $(68.5 \%)$ having only biopsy lived one month or less. The comparable figures for total and incomplete excision were 35 of $108(32.2 \%)$ and 23 of $56(41 \%)$ respectively. It is not possible to discover the natural history of these tumours by considering the untreated group, because all the patients in that group were in very poor condition on admission.

Most of the patients in this series had gross signs on admission. Of the 252 with bronchogenic carcinoma, only 21 had minimal neurological signs, 7 of them with papilloedema ; 105 had hemiparesis or hemiplegia, 47 of them with papilloedema ; and papilloedema was present in 62 of the remaining 126 patients, all of whom were drowsy or disorientated in addition to having localizing signs.

\section{Duration of Symptoms or Signs}

The mean duration of symptoms or signs definitely referable to intracranial metastasis was three months for bronchial carcinoma and four and a half, six, and three 
months respectively for breast, kidney, and gastrointestinal carcinoma, excluding from the latter group four cases of malignant meningitis in all of which the history was one month or less. However long or short the post-operative survival, the duration of the previous history did not vary significantly from the mean.

\section{Solitary Metastases}

Some idea of the possibilities for useful surgery may be gained by considering the incidence at necropsy of solitary metastases, those cases in which no other intracranial or visceral metastases were apparent. The results of the necropsies on patients with bronchogenic carcinoma are given in Table IV. Galluzzi and Payne (1956) found solitary metastases in the brain in $13.9 \%$ of 741 necropsies on patients dying from carcinoma of the bronchus.

TABLE IV.-Multiplicity and Association of Metastases at

\begin{tabular}{l|c|c|c} 
& $\begin{array}{c}\text { Single } \\
\text { Intracranial }\end{array}$ & $\begin{array}{c}\text { Multiple } \\
\text { Intracranial }\end{array}$ & Total \\
\hline $\begin{array}{l}\text { Intracranial only } \\
\text { Associated visceral metastases }\end{array}$ & 24 & 37 & 61 \\
\hline \multicolumn{1}{c|}{ Total } & 15 & 71 & 86 \\
\hline $\begin{array}{l}\text { There were a'co six cases with multiple intracranial metastases and one with } \\
\text { a single metastasis in which there is no record of whether visceral metastases } \\
\text { were present. }\end{array}$
\end{tabular}

In our series 4 out of 27 necropsies performed 2 to 13 months after operation showed the metastasis to be solitary ; and 20 out of 120 necropsies performed within two months of operation revealed a solitary secondary. Consideration of the site and size of the metastasis leaves only five which were definitely suitable for total excision. In four of these the primary growth was resectable, and in the other case no primary was found: four patients had died following the operation on the metastasis. One had lived for seven months before dying from a recurrence: at necropsy no other metastases were seen, and the primary, which had been suspected radiologically at the time of operation, was still small. Nine solitary metastases were found among 59 necropsies on patients with intracranial metastases originating from sites other than bronchus; four of these nine were suitable for total excision. Flavell (1949) found only two solitary metastases among 85 patients with intracranial secondaries from carcinoma of the bronchus. A further eight with single cerebral metastases has hilar-node involvement which was considered operable.

\section{Radiological Estimate of the Occurrence of Single Metastases}

It is not possible to be certain radiologically that an intracranial tumour is a metastasis, or that it is the only one. Two tumours, thought radiologically and at operation to be meningiomas, proved histologically to be carcinoma. Of 92 patients dying within a few days of admission, 33 were correctly diagnosed as having single tumours, and 8 as having multiple. At necropsy 51 in whom only a single tumour could be demonstrated were found to have multiple intracranial metastases.

Malignant Meningitis.-Six examples of malignant meningitis without other intracranial metastases were seen. Four were from the stomach and one each from pancreas and uterus.

\section{Discussion}

The predominance of metastases from bronchogenic carcinoma in this series $(65 \%)$ is similar to other large surveys-Meyer and Reah (1953) finding 53.7\%, and Globus and Meltzer (1942) 57.6\%. Older series give a smaller proportion (see Willis, 1952). Among the more recent series only Störtebecker (1954) differs markedly: $20 \%$ of his 156 cases originated from hypernephroma and only $16 \%$ from bronchial carcinoma.

Deliberate operation on intracranial metastases is usually undertaken for symptomatic relief, and occasionally in an attempt to procure a useful prolongation of life. Sometimes operation for the former achieves the latter. We have particularly noted those patients surviving one year or more after operation (Table V). It is clear that survival for one year is not necessarily synonymous with useful prolongation of life. Six patients remained chronically ill and severely incapacitated for between one and two years. But 16 others remained in good health for a year or more and several returned to work. One man was still doing part-time work six years later.

The major factor in determining the length of postoperative survival seems to be the general physical condition of the patient on admission. Four out of 43 $(9.3 \%)$ patients with minimal neurological signs and in good physical condition survived more than one year. So did 15 out of $163(9.2 \%)$ with marked neurological signs but otherwise in moderately good physical condition. Only 3 out of $183(1.6 \%)$ admitted when drowsy, disorientated, and in poor physical condition survived as long as one year. There was no significant difference in the survival of patients in these groups with or without papilloedema.

Störtebecker (1954) found a longer post-operative survival in patients from whom the primary tumour had previously been excised. Since his long survivals are weighted with an unusual proportion of hypernephromas the general significance of this observation is uncertain. We are unable to reach any conclusion on this point. Most of our patients with carcinoma of breast and kidney had had the primary excised, but it had been excised in only nine of those with carcinoma of the bronchus. It is not possible to compare these different tumours, and the number of cases of bronchogenic carcinoma with previous operation is too small for comparison with those which had not had the primary excised.

Excision of the primary is not always essential for long survival. No primary has yet become evident in one man six years after the excision of a cerebral metastasis. On admission in 1956 he complained of headaches for three months. He was found to have a left hemiparesis but no papilloedema. The chest film was normal. Arteriography and ventriculography confirmed the presence of a large left anterior temporal mass (Special Plate, Figs. 1 and 2). At operation a welldemarcated metastasis was found and was removed in fragments, the largest of which was 5 by 3 by $2 \mathrm{~cm}$. Microscopical examination showed it to be a squamous carcinoma with all the appearances of a secondary deposit, and of high-grade malignancy (Special Plate, Fig. 3). The primary must be exceedingly slow-growing, or perhaps it has undergone partial degeneration or even spontaneous regression. It is just possible that the cerebral metastasis would also have regressed, but in 


\section{P. RICHARDS AND W. MCKISSOCK: INTRACRANIAL METASTASES}

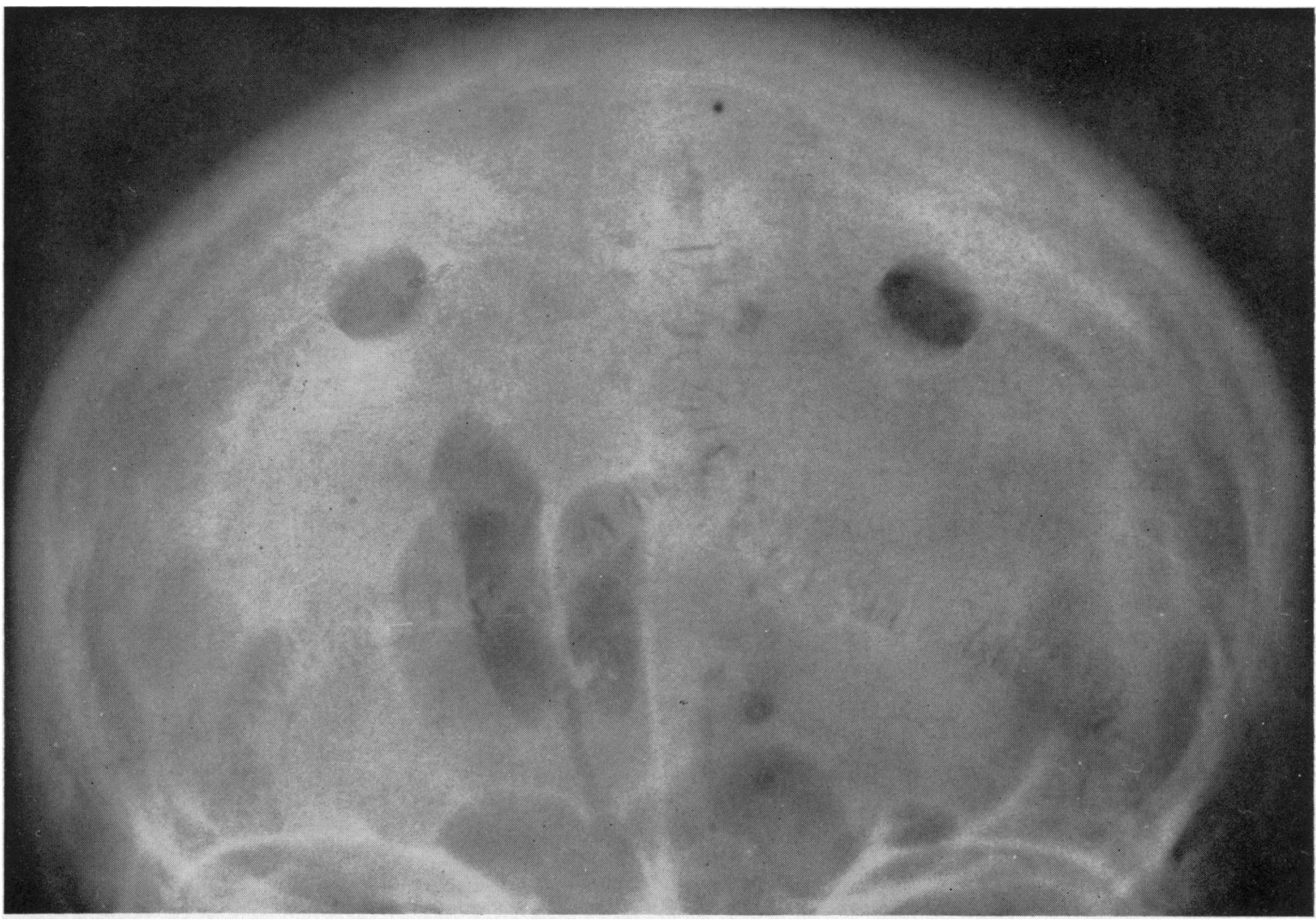

Fig. 1.-Ventriculogram in 1956 showing shift of midline structures from left to right.
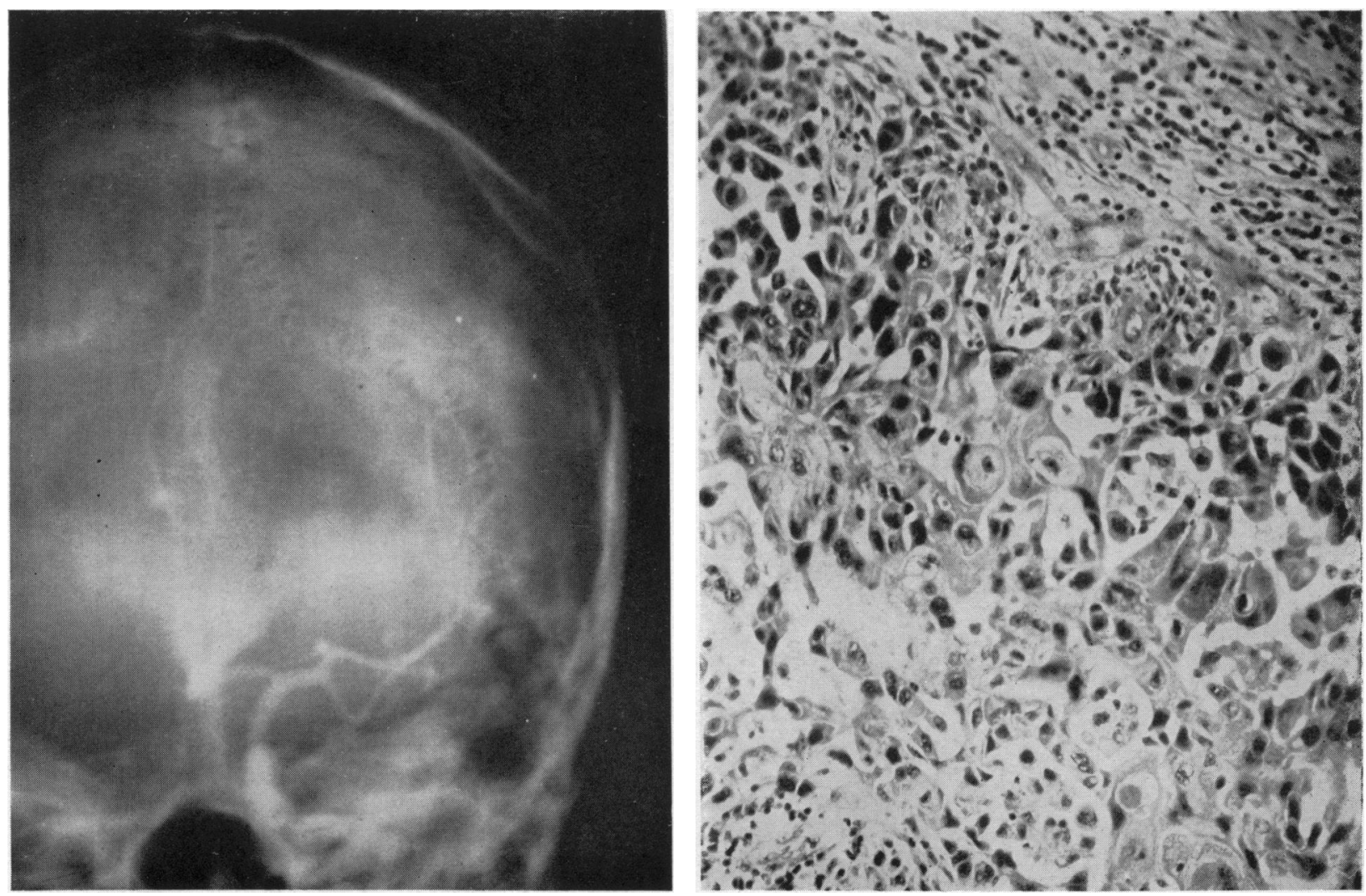

Fig. 2.-Arteriogram in 1956 confirming shift from left to right.

Fig. 3.-Section of metastasis excised in 1956. (H. and E. $\times 150$.) 
view of the progressive symptoms and signs this is unlikely.

Unlike Livingston et al. (1948) we did not find that the longer the history the longer was the post-operative survival. It is, however, clear that the growth of metastases may sometimes be very slow, particularly from breast or kidney. For example, a 42-year-old woman presented with a history of headaches for one year with gradually increasing right weakness. On admission she was alert and orientated, but had papilloedema and a mild right hemiparesis. A carcinoma of the breast had been excised four years previously. After biopsy, which confirmed the presence of a metastasis, she had a course of irradiation without clinical improvement. She gradually deteriorated, dying 14 months later.

Many years may sometimes elapse between excision of a carcinoma and the clinical presentation of a metastasis, which may be solitary. The longest interval in this series was 13 years after the excision of a hypernephroma. Gutmann (1904) records an interval of 18 years between excision of an ovarian carcinoma and clinical evidence of intracranial metastasis.

Since an intracranial secondary may be the only macroscopic metastasis years after the excision of the primary, it is possible in this case that excision of the metastasis may complete a cure. Störtebecker (1954) reports a man alive and in moderate health 17 years after total excision of a single cerebellar metastasis from a hypernephroma which had been previously excised.

Carcinoma of the bronchus presents a particular challenge in that about $17 \%$ (Bryson and Spencer, 1951) to $26 \%$ (Galluzzi and Payne, 1956) develop intracranial metastases, sometimes early in the course of the disease. In about $14 \%$ of these cases there is a single intracranial secondary and no visible visceral metastases. Approximately one-quarter of these will be suitable for excision of both primary and metastasis if the patient's general condition is good.

In those cases in which the metastasis presents at a time when chest film, bronchoscopy, and exfoliative cytology are negative, years may pass before the primary appears. Every patient from whom a metastasis has been excised and no primary has been discovered shculd be regularly followed up, with particular reference to the chest. Russell and Rubinstein (1959) report the case of a man of 54 from whom a left occipital metastasis was excised in 1948. The chest film was normal. Four years later he returned with haemoptysis and pain in the left upper chest and arm. A left apical carcinoma was demonstrated and resected. He died in 1954, six years after the excision of the metastasis. Multiple subarachnoid and subdural deposits were found, together with a plaque of tumour at the craniectomy site. There was no sign of visceral metastases or of local recurrence of the primary.

These authors also suggest that metastases from bronchial carcinoma are not always as rapidly progressive as our cases suggest. Two men are quoted who had a history of Jacksonian epilepsy starting four and a half and three years respectively before death. Posterior frontal metastases from carcinoma of the bronchus were found in both cases.

For periods of at least a year after excision an intracranial metastasis may not recur, nor do others always develop even if the primary is still present. A

TABLE V.-Survival for One Year or Longer after Operation on Intracranial Metastasis

\begin{tabular}{|c|c|c|c|c|c|c|c|c|}
\hline Age & Sex & $\begin{array}{c}\text { Condition } \\
\text { on } \\
\text { Admission* }\end{array}$ & $\begin{array}{l}\text { Symptoms } \\
\text { or Signs } \\
\text { (Months) }\end{array}$ & $\begin{array}{c}\text { Site } \\
\text { of } \\
\text { Metastasis }\end{array}$ & Surgical Treatment & $\begin{array}{l}\text { Post-op. } \\
\text { Radiotherapy to } \\
\text { Metastasis Site }\end{array}$ & $\begin{array}{c}\text { Survival } \\
\text { (Months) }\end{array}$ & Notes \\
\hline
\end{tabular}

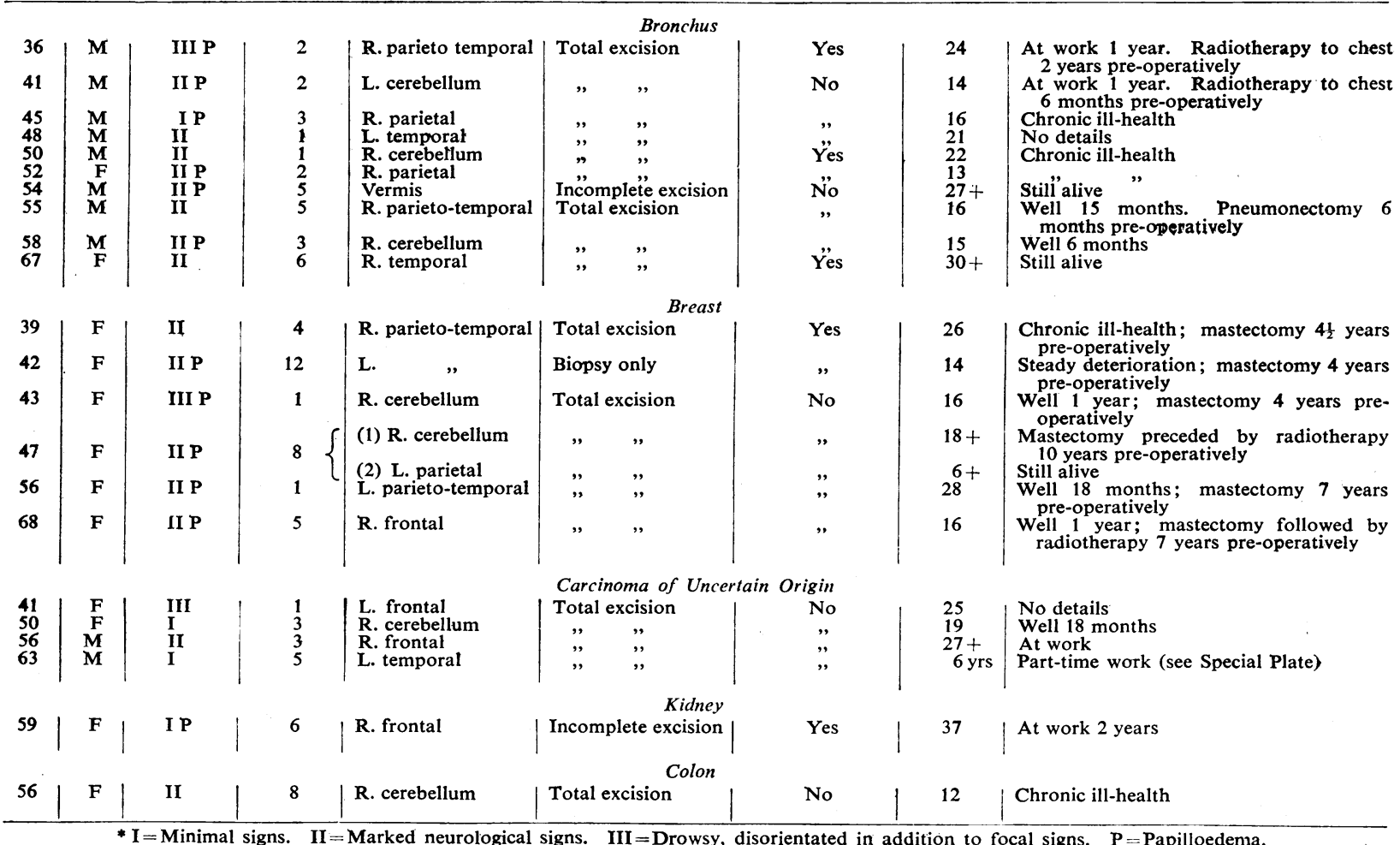


42-year-old man had a cerebellar metastasis excised in 1954. Several months later a bronchial carcinoma was discovered and treated with a course of irradiation. At necropsy 14 months after the operation there were no cerebral metastases and no recurrence at the operation site.

Finally we return to the possibility of the spontaneous regression of tumours, a subject fully discussed by Everson and Cole (1956), and recently commented on by Smithers (1962). A 53-year-old woman was seen in 1938 complaining of headaches for six weeks with gradual onset of dysphasia and right hemiparesis. A well-demarcated tumour was found at a depth of $3 \mathrm{~cm}$. in the left parietal cortex and was enucleated. Sections of the tumour were seen by several histologists, who were agreed that this was a metastasis from a hypernephroma: in 1942 the sections were reviewed and the diagnosis was upheld. After the operation the dysphasia and hemiparesis cleared almost completely. Later in 1938 a laparotomy was performed at St. Mary's Hospital, but both kidneys appeared normal. Intravenous and retrograde pyelograms in 1941 were normal. In 1955 , at the age of 70 , she was alive and well, and a regular attender at the follow-up clinic with her husband, from whom an acoustic neuroma had been excised.

\section{Conclusions}

The surgical excision of an apparently single intracranial metastasis is worth while if the patient is in good general physical condition, and particularly if a primary tumour of breast or kidney has previously been excised.

Biopsy of intracranial metastases carries a very high mortality and morbidity; if it were possible to make a confident diagnosis that an intracranial tumour was a metastasis by other means, suitable cases could be selected for total excision of the secondary, while the majority could be spared useless and time-consuming surgical procedures.

Patients from whom a metastasis of uncertain origin has been excised should be followed up regularly, with particular reference to the diagnosis of a bronchial carcinoma as soon as it becomes detectable, and before it is inoperable.

Very occasionally years of reasonable health may follow excision of an intracranial metastasis, even if the primary tumour is not found and excised.

\section{Summary}

In an analysis of 389 patients with intracranial metastases the commonest primary sites were found to be lung $(65 \%)$, breast $(5.9 \%)$, gastro-intestinal tract $(4.9 \%)$, and kidney $(2.8 \%)$, while $17 \%$ were of uncertain origin. Up to 13 months after operation 213 necropsies were performed, and in 33 no other intracranial or visceral metastases were found.

It was usually not possible to be certain clinically or radiologically that a tumour was a metastasis. Biopsy was associated with a high mortality and morbidity: $68.5 \%$ of those with carcinoma of breast, bronchus, kidney, or uncertain origin who were submitted to it lived only one month or less. The mortality for total excision and incomplete excision of the metastasis in these groups was $32.2 \%$ and $41 \%$ respectively.

Twenty-two patients survived for one year or longer, 10 with carcinoma of the bronchus, six with carcinoma of the breast, four of uncertain origin, and one each with carcinoma of colon and kidney. Total excision of the metastasis was performed in 18 cases, incomplete excision in two, biopsy in one, and in one case total excision of cerebral metastasis was followed a year later by total excision of a cerebellar metastasis. One man was still alive 6 years after the total excision of a cerebral metastasis.

Operation was not rewarding on patients in poor general physical condition on admission: $9.3 \%$ of 43 with minimal neurological signs and in good physical condition survived more than one year, as did $9.2 \%$ of 163 with marked neurological signs and in moderately good general condition. Only $1.6 \%$ of 183 admitted when drowsy, disorientated, and in poor general condition survived more than one year. There was no significant difference in the survival of patients in these groups whether or not they had papilloedema.

We are grateful to Professor T. Crawford for Fig. 3.

\section{REFERENCES}

Bryson, C. C., and Spencer, H. (1951). Quart. J. Med., 20, 173. Everson, T. C. and Cole, W. H. (1956). Ann. Surg., 144, 366 Flavell, G. (1949). Brit. med. J., 2, 736.

Galluzzi, S., and Payne, P. M. (1956). Brit. J. Cancer, 10, 408.

Globus, J. H., and Meltzer, T. (1942). Arch. Neurol. Psychiat. (Chic.), 48, 163.

Gutmann, C. (1904). Fortschr. Med., 22, 141

Livingston, K. E., Horrax, G., and Sachs, E. (1948). Surg. Clin. N. Amer., 28, 805.

Meyer, P. C., and Reah, T. G. (1953). Brit. J. Cancer, 7, 438

Russell, D. S., and Rubinstein, L. J. (1959). Pathology of Tumours of the Nervous System, p. 219.

Tumours of the Nervous System, $\mathrm{p}$.
Smithers, D. W. (1962) Lancet, $1,493$.

Smithers, D. W. (1962), Lancet, 1, 493.

Wtörtebecker, T. P. (1954). J. Neurosurg., 11, 84. p. 255. Butterworth, London.

\section{CELLULAR INFILTRATION IN HOMOTRANSPLANTED KIDNEYS}

BY

\section{W. J. DEMPSTER, F.R.C.S.}

AND

M. A. WILliAMS, M.Sc.

With the Technical Assistance of PETER BURGESS and RICHARD SPARKS

Department of Surgery, Postgraduate Medical School of London

[With Special Plate]

It has been known for several decades that homotransplanted kidneys in dogs become infiltrated with cells. Some authors have considered that this cellular infiltration reflected an infection which terminated the natural life of homotransplanted kidneys (Williamson, 1926; Wu and Mann, 1934). Autotransplanted kidneys, on the other hand, do not become infiltrated with cells. In more recent papers it has been demonstrated that in the early stages of the natural life of a homotransplanted kidney the infiltrating cells are pyroninophilic (Simonsen et al., 1953; Dempster, 1953a). It has also been demonstrated that the cell population radically alters during the period of oliguria and final anuria (Dempster, 1955). In the oliguric-anuric stage the infiltrating cells are easily recognized as polymorphs, histiocytes, and lymphocytes. This cell population, indisputably of host origin, is associated with parenchymal liquefaction in the rejecting kidney. 